\title{
New water treatment technology - homogeneous membrane electrodialysis
}

\author{
Guorui Tang ${ }^{1}$, Kuan $\mathrm{He}^{2, *}$ and Deqing $\mathrm{Liu}^{2}$ \\ ${ }^{1}$ Huadian Electric Power Research Institute Co., LTD, Hangzhou,310030, P.R.China \\ 2 Department of Environment Science and Engineering, North China Electric Power University, No.689, Yonghua North Road, Baoding, \\ Hebei Province, 071000, P.R.China
}

\begin{abstract}
This paper introduces the structure and technical principle of the homogeneous membrane electrodialyzer, and describes that the homogeneous ion exchange membrane has excellent ion exchange capacity, low water loss rate, stable physical and chemical properties and effective removal of organic matter. The homogeneous membrane electrodialysis technology should be combined with other water treatment processes in practice to achieve better treatment results.
\end{abstract}

\section{Introduction}

With the development of industry, the discharge of industrial wastewater is increasing. Industrial wastewater contains a large amount of solid suspended solids, high concentrations of organic matter and salt substances. For industries such as non-ferrous metals, the discharged wastewater also contains heavy metal ions [1]. The highsalt organic wastewater treatment methods mainly include biological methods and physical chemical methods [2]. The biological method can remove higher COD, but the microbial activity is easily affected by the salt concentration of the wastewater. Therefore, the biological method needs to reduce the salt before the wastewater treatment; the physical and chemical method can effectively remove the salt and organic matter in the wastewater, but the general cost is high [3-5]. How to effectively combine physical and chemical treatment methods is of great significance for achieving zero discharge of wastewater.

Membrane method is used in the treatment of industrial wastewater including forward osmosis, reverse osmosis, electrodialysis and other water treatment processes, widely used in metal smelting, petrochemical and other directions [6-7]. At present, the homogeneous membrane electrodialysis technology has been widely used in the field of water treatment such as zero discharge of wastewater due to its characteristics of low energy consumption and high rate concentration.

\section{Homogeneous membrane electrodialysis}

\subsection{Principle of homogeneous membrane electrodialysis technology}

Electrodialysis technology means that under the action of an electric field, the solute particles (such as ions) in the solution migrate through the selection of a permeable semipermeable membrane to achieve the purpose of separating and purifying the substance [8]. The homogeneous membrane electrodialysis technique is to carry a negative charge and a positive charge group on a very thin homogeneous base film by chemical modification methods such as sulfonation and amination to form a cation exchange membrane and an anion exchange membrane. Due to the same-sex repellent and heterogeneous phase attraction, the cation membrane can only selectively permeate the cation, and the anion membrane can only selectively permeate the anion. Compared with the heterogeneous membrane, the homogeneous membrane has better ion exchange performance, more stable membrane performance and can effectively separate organic matter. Therefore, the homogenization membrane electrodialysis concentration efficiency and service life have been greatly improved.

\subsection{Homogeneous membrane electrodialyzer}

The homogeneous membrane electrodialyser consists of an anion-cation exchange membrane, an electrode and a separator. The cation membrane and the anion membrane are interlaced internally, and a plurality of separators are stacked in the middle, and a pair of electrodes are disposed at both ends thereof. When the homogeneous membrane electrodialyzer is working, the raw water is staggered into the separation chamber, and the ions selectively pass through the ion exchange membrane under the action of the direct current electric field, and are concentrated in the adjacent concentration chamber, thereby achieving the purpose of concentration and separation of the salt. Its working principle is shown as in Figure. 1.

\footnotetext{
Corresponding author: lucifertan@163.com
} 


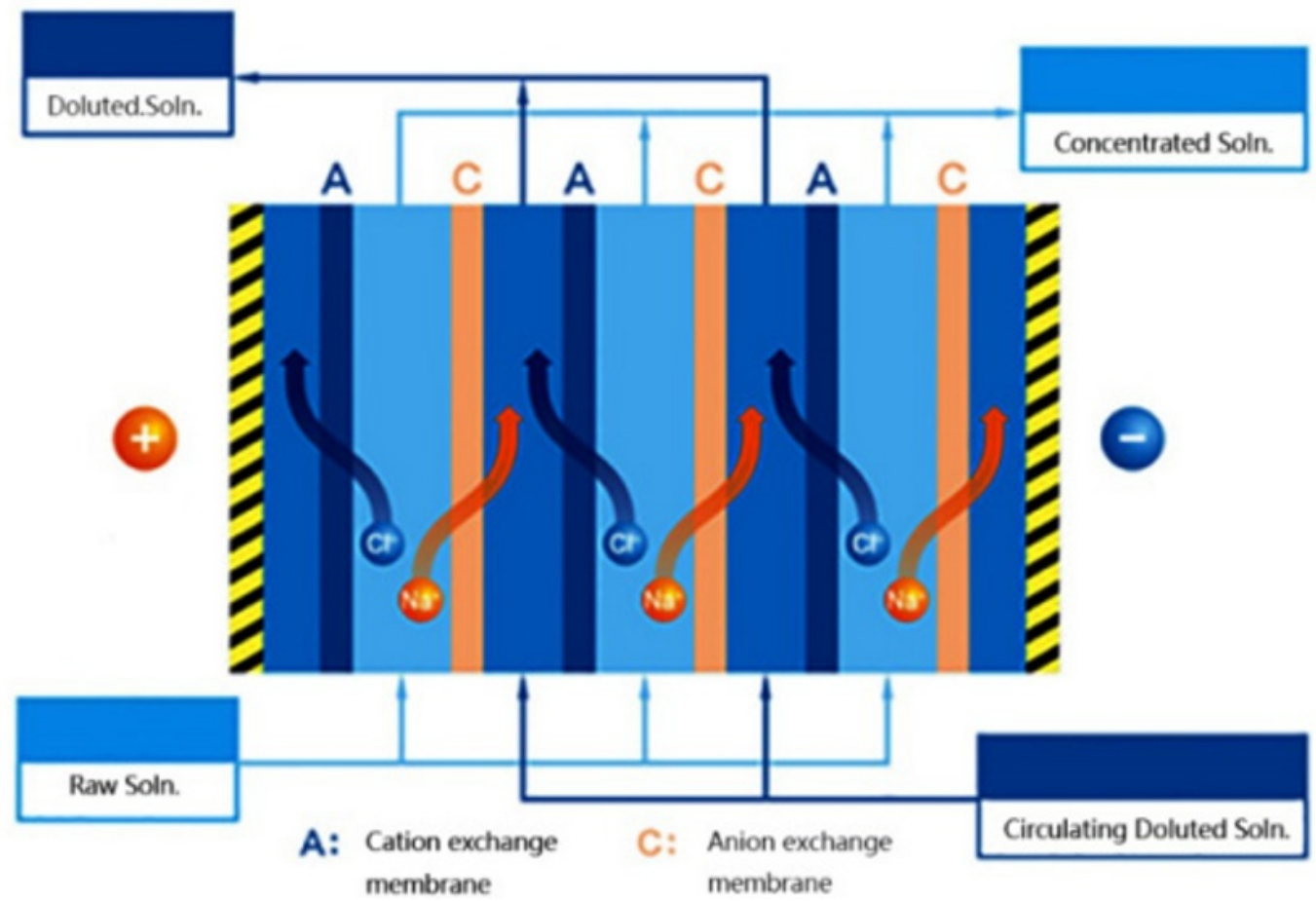

Fig.1.Schematic diagram of homogeneous membrane electrodialysis

Electrolyte with $\mathrm{NaCl}$ runs as different aisle as anodic ion $\mathrm{Na}^{+}$goes through anion exchange membrane, and cathodic ion $\mathrm{Cl}^{-}$goes through cation exchange membrane, respectively.

\section{Characteristics of homogeneous membrane electrodialysis}

The homogeneous ion exchange membrane is formed by polymerizing a high molecular polymer to form a base film, and then chemically modifying to introduce a reactive group. There are many methods for producing homogeneous membranes, such as coating method. At present, most of the homogeneous anion and cation exchange membranes produced in China are made by the coating method [9]. Compared with the heterogeneous film prepared by mixing the ion exchange resin powder and the polymer material, the active film of the homogeneous film is more active, and the connection with the base film is more stable [10], and the film structure has the following characteristics:

\subsection{Strong ion permeability}

The selective permeability of the ion exchange membrane determines the ion exchange capacity, which is expressed by the number of ion transports ( $t$ ), that is, the ratio of the amount of migration of a certain ion in the membrane to the amount of migration of all ions in the membrane [11]. Since the homogeneous membrane contains more active groups, the ion migration number is above 0.96 , which is much higher than the ion migration number of the heterogeneous membrane. The migration of the same amount of ions requires more homogeneous membrane electrodialysis. Less diaphragms make running costs even lower.

\subsection{Low water loss rate}

During the electrodialysis process, due to the concentration difference between the desalination chamber and the concentration chamber and the ion hydration, water molecules migrate from the desalination chamber to the concentration chamber, resulting in water loss. Since the homogeneous membrane is tightly packed, it can avoid high concentration due to excessive water loss and reduce the water loss rate. The water loss rate can generally be controlled at about $10 \%$.

\subsection{Stable physicochemical properties}

The membrane structure determines physical and chemical properties such as membrane resistance, mechanical strength, and stability. The homogeneous ion exchange membrane contains an insert polymer and a reinforced fabric. The surface of the membrane is chemically modified to have stable reactive groups, and the mechanical strength and thermal stability are stronger, so the service life is longer than that of the heterogeneous membrane. And through the improved film forming process, the thickness of the homogeneous ion exchange membrane can be made lower, the membrane surface resistance is smaller, the current efficiency is improved, and the energy consumption is reduced.

\subsection{Effective separation of organic matter}

The homogeneous ion exchange membrane is dense and non-porous, allowing only ions and partially charged organic matter to pass through, and the uncharged COD remains in the light chamber, thereby achieving the purpose of separating organic matter. 


\section{Compared with other processes}

The homogeneous ion exchange membrane has the characteristics of large ion exchange capacity, low operating energy consumption and long service life, so the homogeneous electrodialysis process has better effects than other water treatment process, and other process pairs as shown in Table 1 .

Table 1. Comparison of homogeneous membrane electrodialysis and other process

\begin{tabular}{|c|c|c|c|}
\hline & $\begin{array}{l}\text { Homogeneous membrane } \\
\text { electrodialysis }\end{array}$ & $\begin{array}{c}\text { Thermal method (MVR, multi-effect } \\
\text { evaporation ) }\end{array}$ & $\begin{array}{c}\text { Pressure film } \\
\text { (RO, DT/STRO) }\end{array}$ \\
\hline $\begin{array}{c}\text { Energy } \\
\text { consumption }\end{array}$ & $\begin{array}{l}\text { The ions migrate under the driving } \\
\text { force of electricity, no phase change } \\
\text { process occurs, and the energy } \\
\text { consumption is low. The TDS of the } \\
\text { wastewater is concentrated from } 3 \% \text { to } \\
20 \% \text {, and only } 10-12 \mathrm{kWh} / \text { ton of water } \\
\text { is need. }\end{array}$ & $\begin{array}{l}\text { High energy consumption, need to } \\
\text { overcome the latent heat of phase } \\
\text { change of water, handle one ton of } \\
\text { wastewater, multi-effect evaporation } \\
\text { requires } 0.35 \text { tons of steam, } 10-15 \mathrm{kWh} \\
\text { of electricity; MVR requires } 30-35 \mathrm{kWh} \\
\text { of electricity. }\end{array}$ & $\begin{array}{l}\text { Low energy } \\
\text { consumption, } \\
\text { affected by work } \\
\text { pressure }\end{array}$ \\
\hline $\begin{array}{c}\text { Concentration } \\
\text { effect }\end{array}$ & $\begin{array}{c}\text { High concentration efficiency, the TDS } \\
\text { of wastewater can be concentrated to } \\
\text { more than } 20 \%\end{array}$ & $\begin{array}{c}\text { Concentration effect is affected by heat } \\
\text { transfer efficiency }\end{array}$ & $\begin{array}{l}\text { Concentration } \\
\text { efficiency is general, } \\
\text { affected by working } \\
\text { pressure, it is } \\
\text { difficult to increase } \\
\text { the concentrated side }\end{array}$ \\
\hline $\begin{array}{l}\text { Separation of } \\
\text { organic } \\
\text { matter }\end{array}$ & $\begin{array}{c}\text { It can realize the separation of organic } \\
\text { matter and salt, and it can pre-process } \\
\text { the subsequent evaporation } \\
\text { crystallization. }\end{array}$ & $\begin{array}{c}\text { Organic matter is easily concentrated in } \\
\text { the evaporator and cannot be } \\
\text { effectively separated }\end{array}$ & $\begin{array}{l}\text { Separable organic } \\
\text { matter, but easy to } \\
\text { accumulate on the } \\
\text { concentrated side }\end{array}$ \\
\hline $\begin{array}{l}\text { Cost and } \\
\text { maintenance }\end{array}$ & $\begin{array}{c}\text { Low cost of construction, investment } \\
\text { cost is only half of MVR, and daily } \\
\text { maintenance is simple }\end{array}$ & $\begin{array}{l}\text { Heat treatment method has high } \\
\text { investment, high energy consumption. } \\
\text { The heat transfer device is easy to scale } \\
\text { and accumulate organic matter, and the } \\
\text { maintenance amount is large. }\end{array}$ & $\begin{array}{l}\text { Lower cost, but } \\
\text { facilities such as } \\
\text { equipment and } \\
\text { ancillary pipelines } \\
\text { are susceptible to } \\
\text { stress }\end{array}$ \\
\hline
\end{tabular}

\section{Conclusion}

As a new type of electrodialysis technology, homogeneous membrane electrodialysis technology has homogeneous membrane electrodialysis technology because of its excellent ion exchange capacity, low water loss rate and stable physical and chemical properties. With low energy consumption and high removal rate. It can realize high-concentration of high-salt organic wastewater and recycle water production to meet emission requirements. However, in practical application, attention should be paid to the characteristics of water quality, and effective combination with other water treatment processes, while reducing the cost, improving the desalination efficiency, and finally achieving zero discharge of wastewater.

\section{References}

1. O Lefebvre, R Moletta. Water Res.,40 3671 (2006)

2. D Hendricks, D Hendricks. 7265 (2010)

3. I Metcalfeddy , G Tchobanoglous. H D Stensel. Hydrology for Engineers , 7350 (2003)

4. A Fakhru'L-Razi, A Pendashteh, L C Abdullah. J. Hazard. Mater., 170530 (2009)
5. H J Wang,R P Liu, J H Qu. J. Chem. Technol. Biotechnol. , 84966 (2010)

6. X Ning, Q Li. Chem. Eng. of Oil Gas, 42528 (2013)

7. S S Madaeni, A Gheshlaghi,F Rekabdar. Asia pacific Journal of Che. Eng., 845 (2013)

8. D C Ge, Membr. Sci. Technol., 4202 (2003)

9. K N Mani. J. Membr. Sci., 58117 (1991)

10. G E Molau. J. Membr. Sci., 8309 (1981)

11. G X Abe. Chemical Industry Press (1993) 